\title{
A Metabolic Regulator Modulates Virulence and Quorum Sensing Signal Production in Pectobacterium atrosepticum
}

\author{
Marion F. Cubitt, ${ }^{1,2}$ Peter E. Hedley, ${ }^{2}$ Neil R. Williamson, ${ }^{1}$ Jenny A. Morris, ${ }^{2}$ Emma Campbell, ${ }^{2}$ \\ Ian K. Toth, ${ }^{2}$ and George P. C. Salmond ${ }^{1}$ \\ ${ }^{1}$ Department of Biochemistry, University of Cambridge, Tennis Court Road, Cambridge, CB2 1QW, U.K.; ${ }^{2}$ Cell and Molecular \\ Sciences, James Hutton Institute, Invergowrie, Dundee DD2 5DA, U.K.
}

Submitted 5 September 2012. Accepted 24 October 2012.

\begin{abstract}
Plant cell wall-degrading enzymes (PCWDE) are key virulence determinants in the pathogenesis of the potato pathogen Pectobacterium atrosepticum. In this study, we report the impact on virulence of a transposon insertion mutation in the metJ gene that codes for the repressor of the methionine biosynthesis regulon. In a mutant strain defective for the small regulatory RNA $r s m B$, PCWDE are not produced and virulence in potato tubers is almost totally abolished. However, when the metJ gene is disrupted in this background, the $r s m B^{-}$phenotype is suppressed and virulence and PCWDE production are restored. Additionally, when metJ is disrupted, production of the quorum-sensing signal, $N$-(3-oxohexanoyl)-homoserine lactone, is increased. The metJ mutant strains showed pleiotropic transcriptional impacts affecting approximately a quarter of the genome. Genes involved in methionine biosynthesis were most highly upregulated but many virulence-associated transcripts were also upregulated. This is the first report of the impact of the MetJ repressor on virulence in bacteria.
\end{abstract}

Pectobacterium atrosepticum is a gram-negative phytopathogen that infects potato plants in temperate climates. P. atrosepticum infection causes two distinct diseases: soft rotting of tubers and blackleg disease of the plant stem. The pathology of both of these diseases is principally, but not exclusively, caused by the coordinated secretion of a barrage of plant cell wall-degrading exoenzymes (PCWDE) which degrade plant tissues (Toth and Birch 2005). Release of these exoenzymes, including isoenzymic forms of proteases (Prt), endoglucanases, polygalacturonases, and pectate lyases (Pel), is controlled by a variety of control systems, including quorum sensing (QS) and the RsmAB post-transcriptional regulation system (Barnard et al. 2007; Lapouge et al. 2008; Liu et al. 2008; Romeo 1998; Whitehead et al. 2002).

QS is an intercellular communication system widespread throughout many bacterial species. This mechanism relies on freely diffusible $N$-acyl homoserine lactone molecules produced throughout growth. At low cell densities, the concentration of the molecule is too low to elicit a response. However, at high

Corresponding author: G. P. C. Salmond: E-mail: gpcs2@cam.ac.uk

* The $e$-Xtra logo stands for "electronic extra" and indicates that four supplementary tables and two supplementary figures are published online.

C 2013 The American Phytopathological Society cell densities, the concentration of the signaling molecule reaches a threshold level and interacts with a cognate receptor protein causing transcriptional changes in the organism (Miller and Bassler 2001). In the paradigm model of QS in Vibrio fischeri, the signaling molecule is synthesized by the enzyme LuxI. The signaling molecule then interacts with its cognate receptor protein, LuxR (Fuqua et al. 1994). P. atrosepticum produces the signaling molecule $\mathrm{N}$-(3-oxohexanoyl)-homoserine lactone (OHHL), synthesized by the enzyme ExpI. At high concentrations, this molecule binds to VirR, the primary QS transcriptional regulator. The current model is consistent with VirR acting as a global repressor protein that inhibits production of PCWDE and other virulence factors. When bound to OHHL, this repression is released and virulence determinants are expressed. Repression in the absence of OHHL also occurs via direct transcriptional activation of the global repressor gene, $r s m A$. A further LuxR homologue, ExpR, has also been identified in the genome of this strain of P. atrosepticum. However, in strain SCRI 1043, a mutant defective in this gene has no discernible phenotype in either a wild-type, virR ${ }^{-}$, or expI background and its function remains unknown (Burr et al. 2006; Monson et al. 2012).

Another key regulatory mechanism in P. atrosepticum is the regulator of secondary metabolism (Rsm) system. This involves a global repressor protein, RsmA, and a small regulatory RNA, rsmB. RsmA, a homologue of the Escherichia coli CsrA protein (Romeo et al. 1993), is a small protein of $6.8 \mathrm{kDa}$ which binds to GGA motifs on target mRNAs, commonly around the Shine-Dalgarno sequence. This usually impairs transcript stability and translation of the message, although there is evidence that CsrA is also able to stabilize transcripts (Wei et al. 2001). The small RNA, $r \operatorname{smB}$, contains several stem-loop structures with GGA motifs on the loops which bind RsmA. This results in $r s m B$ effectively out-competing the target transcripts for RsmA binding, increasing target mRNA stability and translation of Rsm-regulated messages (Lapouge et al. 2008). Together, RsmA and $r s m B$ are major regulators of virulence in Pectobacterium spp. (Liu et al. 1998). The effect of this post-transcriptional regulation system is phenotypically dramatic, since an $r s m B$ mutant strain is almost totally avirulent due to uninhibited repression of virulence factors by RsmA. Although a mutant defective in $r s m A$ has not yet been isolated in this strain, homologous mutations in other closely related organisms confer a hypervirulent phenotype and growth impairment (Cui et al. 1995). Therefore, the stoichiometric relationship of this RNA and repressor protein is clearly vital to striking a balance between virulence and fitness of the organism. 
The initial aim of this study was to investigate the Rsm system in $P$. atrosepticum further through the creation of an rsmA mutant strain. The screen designed to identify such a mutant was to conduct a random transposon mutagenesis on a nonvirulent $r s m B$ mutant, using the protease-negative $\left(\mathrm{Prt}^{-}\right)$phenotype as a simple indicator assay. Mutant colonies could then be screened for a restored ability to produce Prt, the logic being that the lack of the RsmA repressor partner in an $r s m B$ mutant background would result in restoration to an easily observable wild-type (or perhaps even "hyper") phenotype, as seen in other species. However, this screening approach led to the unexpected discovery of $r s m B$ suppression through mutations in a metabolic regulatory gene (metJ) not previously linked to pathogen virulence. The MetJ regulator in $P$. atrosepticum has now been shown to interact with the QS and Rsm systems and to impact on virulence in planta.

\section{RESULTS}

\section{Construction and phenotypic analysis} of an $r s m B$ mutant strain, NW155.

In order to investigate the phenotypes regulated by the RsmA/B system in $P$. atrosepticum, an $r s m B$ mutant strain was constructed (as described in Materials and Methods). This strain (NW155) completely lacked the $r s m B$ coding sequence, which had been replaced by a kanamycin resistance cassette. The mutant displayed no growth defect but Prt and Pel activity was undetectable in culture media and the strain showed strongly reduced virulence in plant infection (Figs. 1 and 2). This strain could be complemented with a wild-type copy of the $r s m B$ gene supplied in trans (Apagyi 2012).

\section{Transposon mutagenesis screen.}

Due to the clear $\mathrm{Prt}^{-}$phenotype displayed by NW155, this strain could be used as background to screen for mutations in genes able to bypass the Rsm system. This would potentially include the $\operatorname{rsm} A$ gene, because the repression caused by free RsmA should be relieved in an $\operatorname{rsm} A B$ double mutant. Therefore, NW155 was used as the recipient in a conjugation with donor strain $\beta 2163$ (pDS1028). This plasmid was loaded with a transposon conferring resistance to chloramphenicol and containing the uidA reporter gene. With the aim of identifying an insertion in $r s m A$, transconjugants were screened for restored Prt production. Over 27,000 colonies were screened and three $\mathrm{Prt}^{+}$"revertants" were shown to carry independent insertions in the gene metJ, a homologue of the gene coding for the E. coli repressor of the methionine regulon. A fourth $\mathrm{Prt}^{+}$revertant carried an insertion in the virulence regulator, hexY. It was not unexpected to find an insertion in $h e x Y$, because mutation of this gene has been shown previously to enhance PCWDE production (Shih et al. 1999). The three mutations in the metJ coding sequence were an unexpected finding, with insertions present at 38, 167, and 205 bp into the 318-bp open reading frame. The insertion at $38 \mathrm{bp}$ was in the sense orientation, such that a metJ::uidA transcriptional fusion was formed; therefore, further work was carried out on this mutant, named strain MC2.1.

The metJ mutation was transduced using the generalized transducing phage $\Phi \mathrm{\Phi} 1$ from strain MC2.1 into wild-type Pba1043, to produce strain MC1. This MC1 strain gave a $\mathrm{Prt}^{+}$ phenotype similar to the wild type (Fig. 1A). The functional wild-type met $J$ gene was cloned into the Qiagen vector pQE80L and, when present in the double-mutant strain MC2.1, restored this to a $\mathrm{Prt}^{-}$phenocopy of the progenitor $\operatorname{rsmB}$ mutant strain (Fig. 1B). This demonstrated genetically that it was, indeed, the metJ mutation that caused the corresponding phenotypic changes. Both strains carrying the insertion in metJ displayed a slight growth defect (compared with wild-type and NW155 strains) in pectate minimal medium. Although the shape of the growth curve was identical, the absolute optical density at 600 $\mathrm{nm}\left(\mathrm{OD}_{600}\right)$ values were reproducibly lower, maintaining stationary phase at an $\mathrm{OD}_{600}$ of approximately 3.5 compared with a value of approximately 5 for the wild type.

Although the initial aim of the screen was to identify an $\operatorname{rsm} A$ mutant, this aspect of the screen was unsuccessful. The creation of such a mutant in this bacterial strain has been attempted many times previously by random mutagenesis and allelic exchange methods but met with no success. Studies in other $\gamma$-proteobacteria have indicated that, in some organisms, knockout of $r s m A$ (or the homologous gene $\operatorname{csr} A$ ) may be either lethal or conditionally lethal (Langridge et al. 2009; Timmermans and Van Melderen 2009), which could explain the lack of success in this aspect of the screen.

\section{A metJ mutation partially restores virulence in an $r \mathrm{smB}$ mutant strain.}

Liquid assays for Pel and Prt activity were performed on culture supernatant from stationary phase cultures of wild-type cells and strains NW155, MC1, and MC2.1 (mutated in $r \operatorname{smB}$, $m e t J$, or both $r s m B$ and metJ, respectively). These assays showed that, in a met $J$ mutant, PCWDE production was slightly lower than wild-type levels whereas, in an $r s m B$ mutant, PCWDE activity was almost totally abolished. However, in the rsmB metJ double mutant, exoenzyme activity was partially restored to the level equivalent to that seen in the met $J$ mutant strain (Fig. 2A). To test whether these changes were reflected

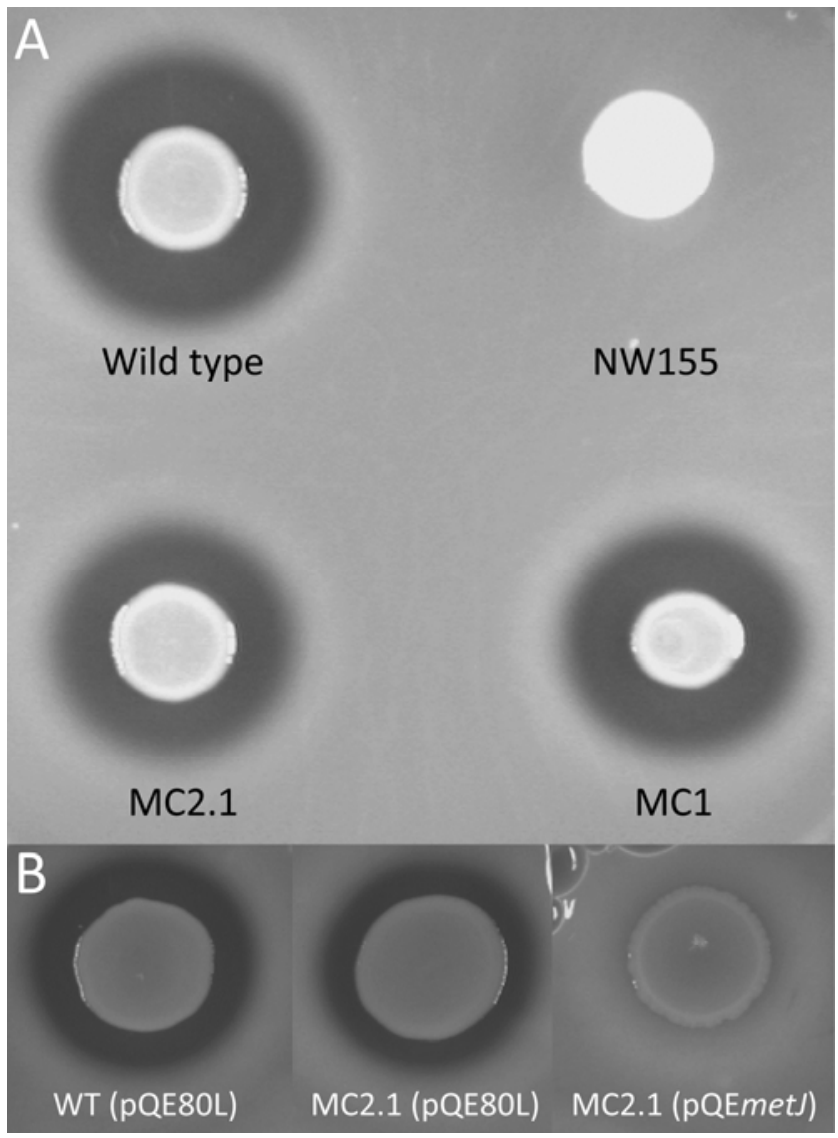

Fig. 1. A, Skimmed milk agar plate showing protease production in wild type and NW155 (rsmB mutant), MC1 (metJ mutant), and MC2.1 (rsmB metJ double mutant) strains. B, Skimmed milk agar plates showing the complementation of strain MC2.1 with a wild-type copy of metJ supplied in trans. 
in virulence phenotypes, each of the three mutant strains was inoculated into potato tubers and the amount of rotting was measured and compared with that of the wild type (Fig. 2B). The degree of rotting seen in each test strain was compared with that seen in the wild-type controls from the same tubers and analyzed by Student's $t$ test. NW155 was the only test strain to show significantly different rotting levels from those of the wild type $(P<0.05)$. In addition, each strain was inoculated into 20 potato plant stems and the degree of rotting measured over 14 days (Fig. 2C). This appeared to show the same trend as seen in the PCWDE and tuber assays, with the $r s m B$ mutant strain displaying almost no rotting and the rsmB metJ double mutant showing a partial restoration toward wild-type levels. On further analysis of these data, it became apparent that, in the $\operatorname{rsmB}$ metJ double mutant, although a successful infection caused the same amount of rotting as the wild type, establishment of the infection failed more often (Fig. 2D). Taken together, these data on in planta infection strongly reflect the trend seen in the liquid PCWDE assays and confirm that the metJ mutation partially restores virulence to an $r s m B$ mutant strain. These data also suggest that the metJ mutation increases virulence through both mediating the levels of PCWDE production and the process of infection establishment.

\section{A mutation in met J fully restores production} of the OHHL signaling molecule.

The three mutant strains were compared for their ability to produce the QS signaling molecule, OHHL. Culture superna- tant samples were taken throughout growth and tested for OHHL production using a bioluminescent sensor strain. Induction of OHHL production began in late exponential phase but occurred at much lower levels in the $\operatorname{rsm} B$ mutant. However, in both strains carrying the metJ mutation, OHHL induction occurred earlier and to higher concentrations than in the wild type (Fig. 3B). The final concentrations of OHHL in the culture medium were between 5 and $8 \mu \mathrm{M}$ for all four strains. This confirms that OHHL as well as PCWDE production in an $r s m B$ mutant is restored by mutation of metJ.

To test whether it was simply restoration of the QS signaling molecule that was leading to PCWDE production in an $r s m B$ metJ double mutant, strains were grown on specific media to test for exoenzyme production, with varying concentrations of OHHL. The expI mutant TB6 does not produce OHHL and, therefore, also does not produce PCWDE such as Prt. This mutant could be chemically complemented by $0.5 \mu \mathrm{M}$ OHHL, whereas the $r s m B$ mutant NW155 showed no increase in Prt production when supplied with up to $10 \mu \mathrm{M}$ OHHL (Fig 3C). The concentration of $10 \mu \mathrm{M}$ was selected as a maximum because this is higher than levels measured in stationary phase cultures of wild-type $P$. atrosepticum (discussed above). This effect was also seen on cellulase and Pel production (Supplementary Fig. S1). In addition, providing exogenous OHHL to wild-type cultures at the start of growth did not induce early PCWDE production (Fig. 3B). Therefore, the restoration of OHHL production does not appear to be the direct cause of the restoration of virulence seen in this strain.
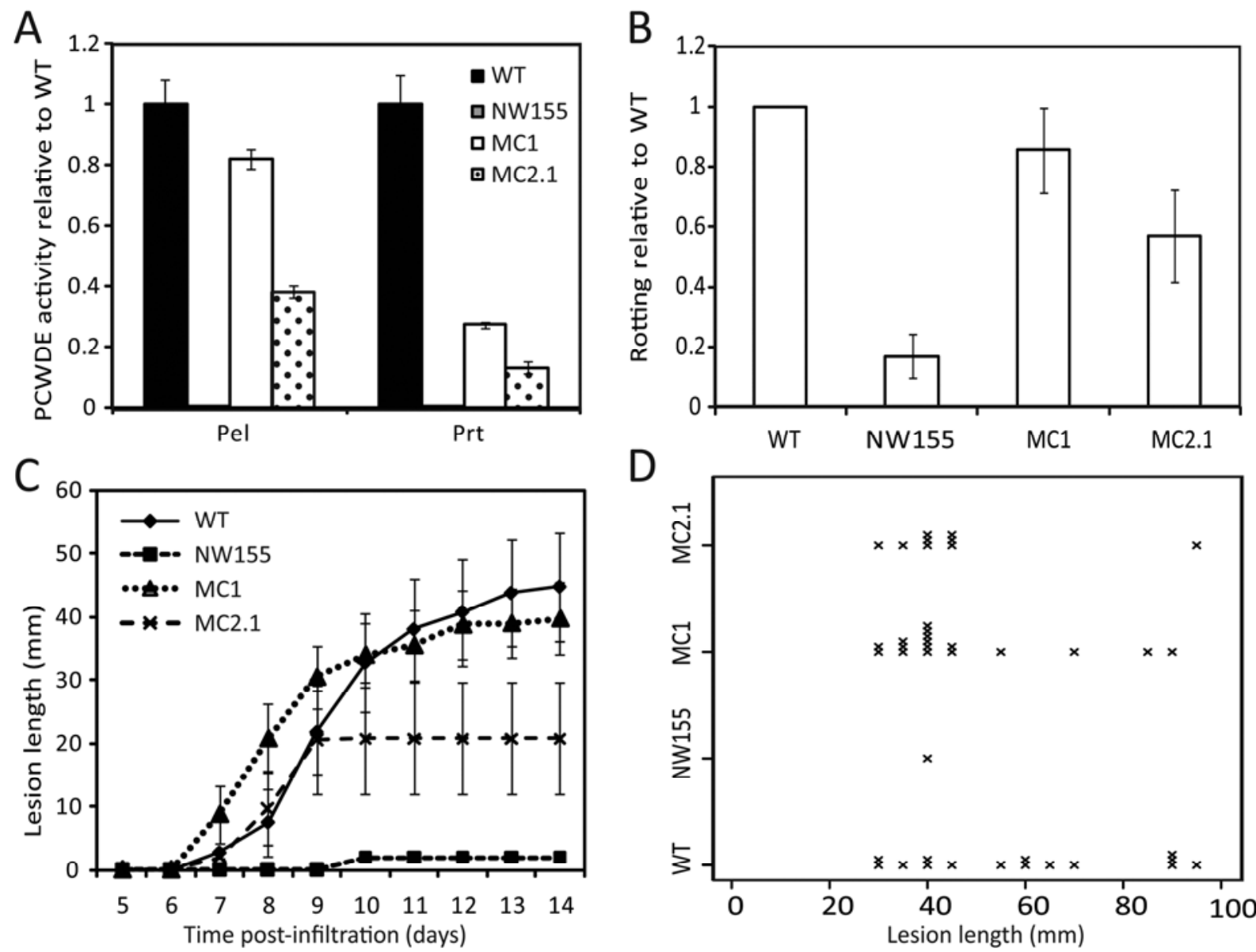

Fig. 2. A, Pectate lyase (Pel) and protease (Prt) activity in stationary phase cultures in wild type and NW155 ( $r s m B$ mutant), MC1 (met $J$ mutant), and MC2.1 (rsmB metJ double mutant) strains. Cultures were grown in pectate minimal media (PMM) at $25^{\circ} \mathrm{C}$. Data for the mutant strains is shown relative to the wild type, which is represented as 1 . B, Rotting in potato tubers as quantified by weighing. Data for the mutant strains is shown relative to the wild type, which is represented as 1 . C, Rotting in potato plant stems as quantified by lesion length measured over 14 days. $\mathbf{D}$, Distribution of rotting in the sample on the 14 th day, with each point representing a successful infection. 
In order to test whether MetJ was affecting OHHL production via transcriptional regulation of the OHHL synthase, levels of the expI transcript were measured by quantitative reversetranscriptase polymerase chain reaction (qRT-PCR). Expression of the expI transcript during late stationary phase was reduced by approximately twofold in an $r \operatorname{smB}$ mutant but increased by 2.8 -fold in the metJ mutant (Fig 3D). These changes in expI expression show the same pattern as for OHHL expression at
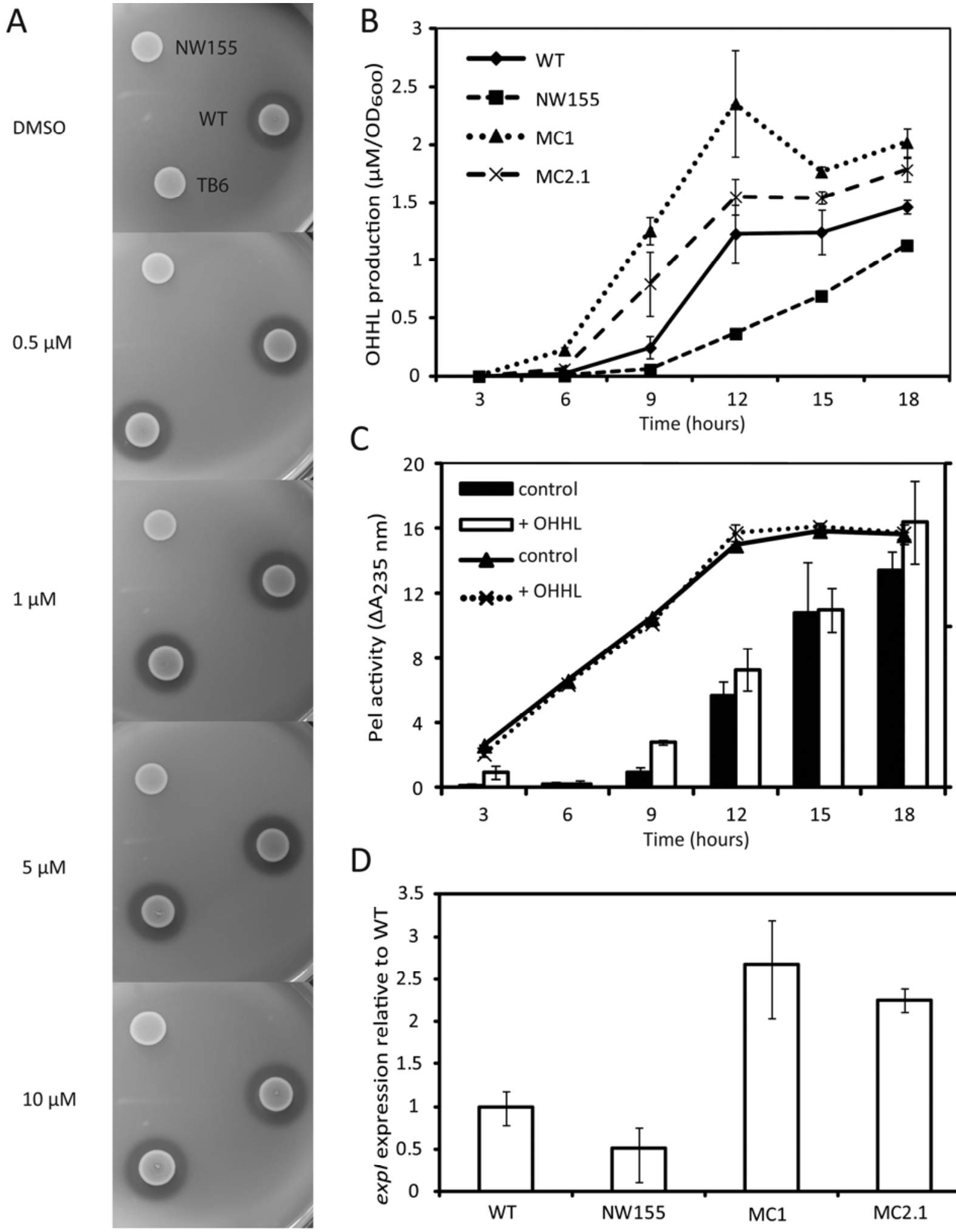

$\mathrm{C}$

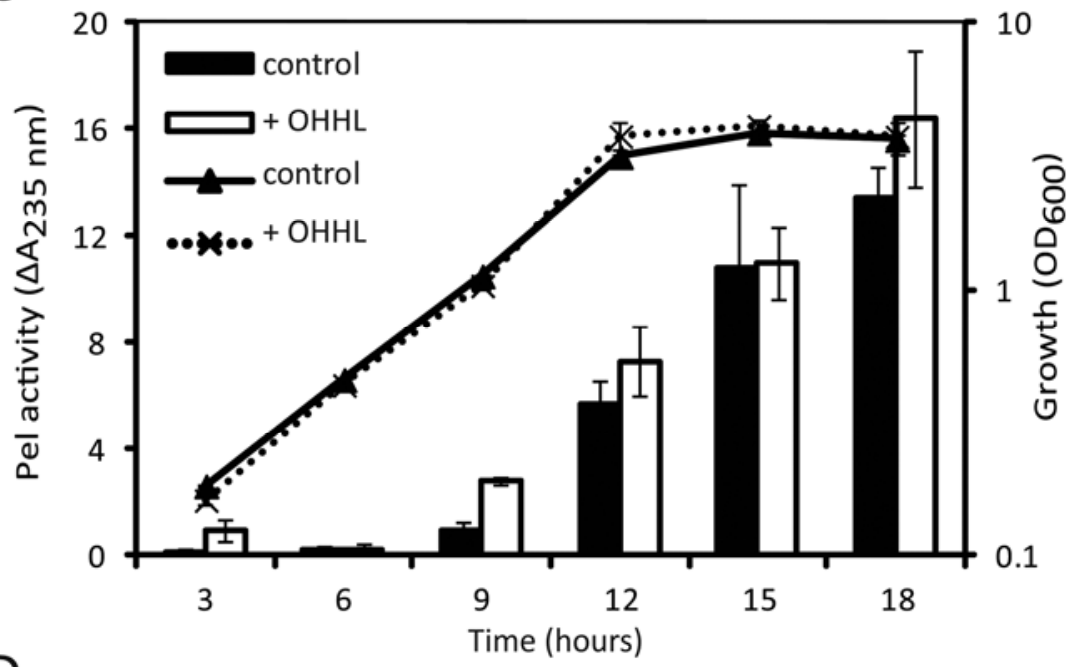

D

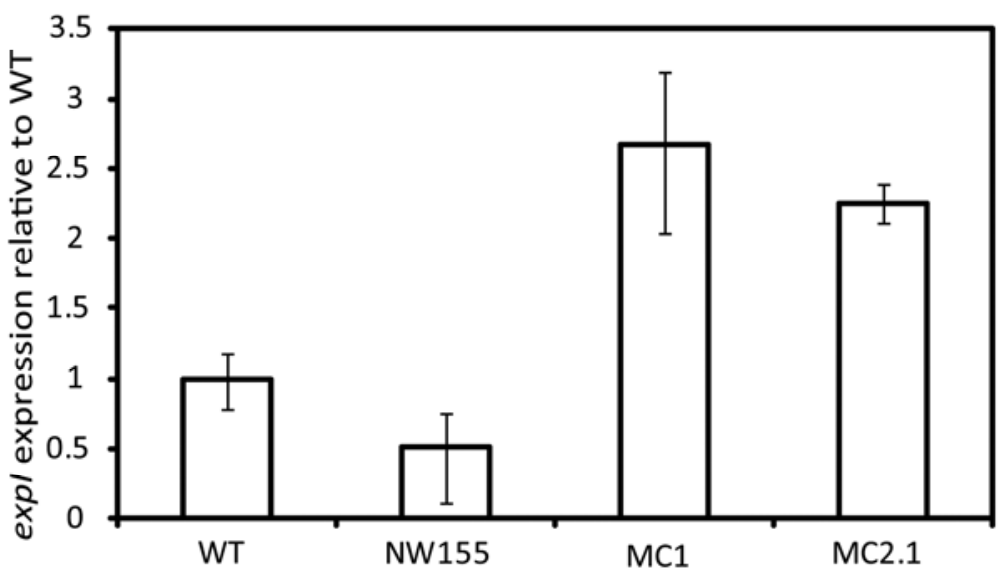

Fig. 3. A, Protease production by NW155 (rsmB mutant; top left), wild type (middle right), and TB6 (expI mutant; bottom left) strains grown on protease agar supplemented with varying concentrations of $\mathrm{N}$-(3-oxohexanoyl)-homoserine lactone (OHHL) or a dimethyl sulfoxide (DMSO) control. B, OHHL production in culture supernatants measured throughout growth. Cultures were grown in pectate minimal media (PMM) at $25^{\circ} \mathrm{C}$. C, Pectate lyase (Pel) activity (bars) in wild-type culture supernatants measured throughout growth (line graphs) in the presence of either $1 \mu \mathrm{M}$ OHHL or a DMSO control. D, Expression of the OHHL synthase gene, expI, in wild type and NW155 (rsmB mutant), MC1 (metJ mutant), and MC2.1 (rsmB metJ double mutant) strains. Quantitative reverse-transcriptase polymerase chain reaction was carried on cDNA generated from RNA samples taken after $18 \mathrm{~h}$ of growth in PMM. 
$18 \mathrm{~h}$ (Fig. 3B). This suggests that modulation of ExpI levels is at least partly responsible for the changes observed in OHHL production.

\section{Bioinformatic analysis of the MetJ regulon.}

Alignment using the National Center for Biotechnology Information BLAST tool (Altschul et al. 1997) revealed a high degree of similarity between the E. coli and $P$. atrosepticum MetJ proteins, with only one of a total of seven amino acid changes occurring in a predicted functional domain (Fig. 4A). Due to the closeness in predicted structure and, therefore, function of these two proteins, genes homologous to those reported to be in the E. coli met regulon (Weissbach and Brot 1991) were predicted as likely targets for MetJ binding in $P$. atrosepticum. Therefore, the promoter regions upstream of these genes would be likely to contain a MetJ binding site.

To identify the $P$. atrosepticum MetJ binding site, the 500-bp regions preceding genes annotated as homologues of genes in the $E$. coli MetJ regulon were analyzed using the "multiple em for motif elicitation" (MEME) tool. The predicted motif from this output was TAGACGTCT $\underline{A}$, identical in sequence to the published E. coli MetJ "met box" AGACGTCT (Belfaiza et al. 1986), flanked by an additional thymine and adenine (underlined). This was not surprising given that the DNA binding domains of E. coli and $P$. atrosepticum MetJ are identical (Fig. 4A). This motif was entered into the "find individual motif occurrences" (FIMO) program to identify locations of this motif in the 500-bp upstream sequences of all annotated genes in the $P$. atrosepticum genome. This search identified 32 genes with $P$ values lower than that for the metK promoter, which is known to be bound by MetJ in E. coli. Therefore, these 32 genes, including several met genes such as met $N$, met $F$, met $B$, $m e t R$, and metE, as well as metJ itself, together with several genes not annotated as being involved in methionine metabo- lism, were provisionally predicted to be regulated directly by MetJ in this organism (Table 1).

\section{Transcriptomic analysis of met J mutant strains.}

To try to define a mechanism for the impact of metJ on virulence phenotypes, a global transcriptomics approach was selected. A $\beta$-glucuronidase reporter gene study had shown that met $J$ was most highly expressed later in growth (Fig. 4B). This was also investigated by qRT-PCR in a wild-type background and indicated that met $J$ expression was increased by 1.31 - and 2.23-fold compared with exponential phase cells during early and late stationary phase, respectively (Supplementary Fig. S2).

Therefore, a microarray study was carried out on late-stationary-phase RNA samples from wild type and $r s m B$, metJ, and $r s m B$ metJ mutant cultures to examine global changes in transcription across the different strains. Each mutant was compared with the wild type and probes were filtered to include only those with a $t$ test significance of $P \leq 0.01$ and a minimum twofold change. This left 254 (160 up, 94 down), 1,136 (812 up, 324 down), and 1,199 (793 up, 406 down) significantly differentially expressed probes between the wild type and the $\operatorname{rsmB}$ and met $J$ single mutants and the double mutant strains, respectively (Supplementary Tables S1, S2, and S3).

The transcriptional changes seen in strains carrying the metJ mutation were numerous and widespread across genes involved in diverse cellular processes. The most striking gene expression changes were among the three genes metA, metE, and metR, which exhibited increases in expression of 90- to 100-fold in the metJ mutant and 110- to 130-fold in the rsmB metJ mutant. Another gene showing similar levels of upregulation in these mutants was ECA1113, a putative methionine synthase identified as having a met box in its promoter region in both this study (Table 1) and by Augustus and Spicer (2011). Taken with the evidence that it is differentially regulated to a degree

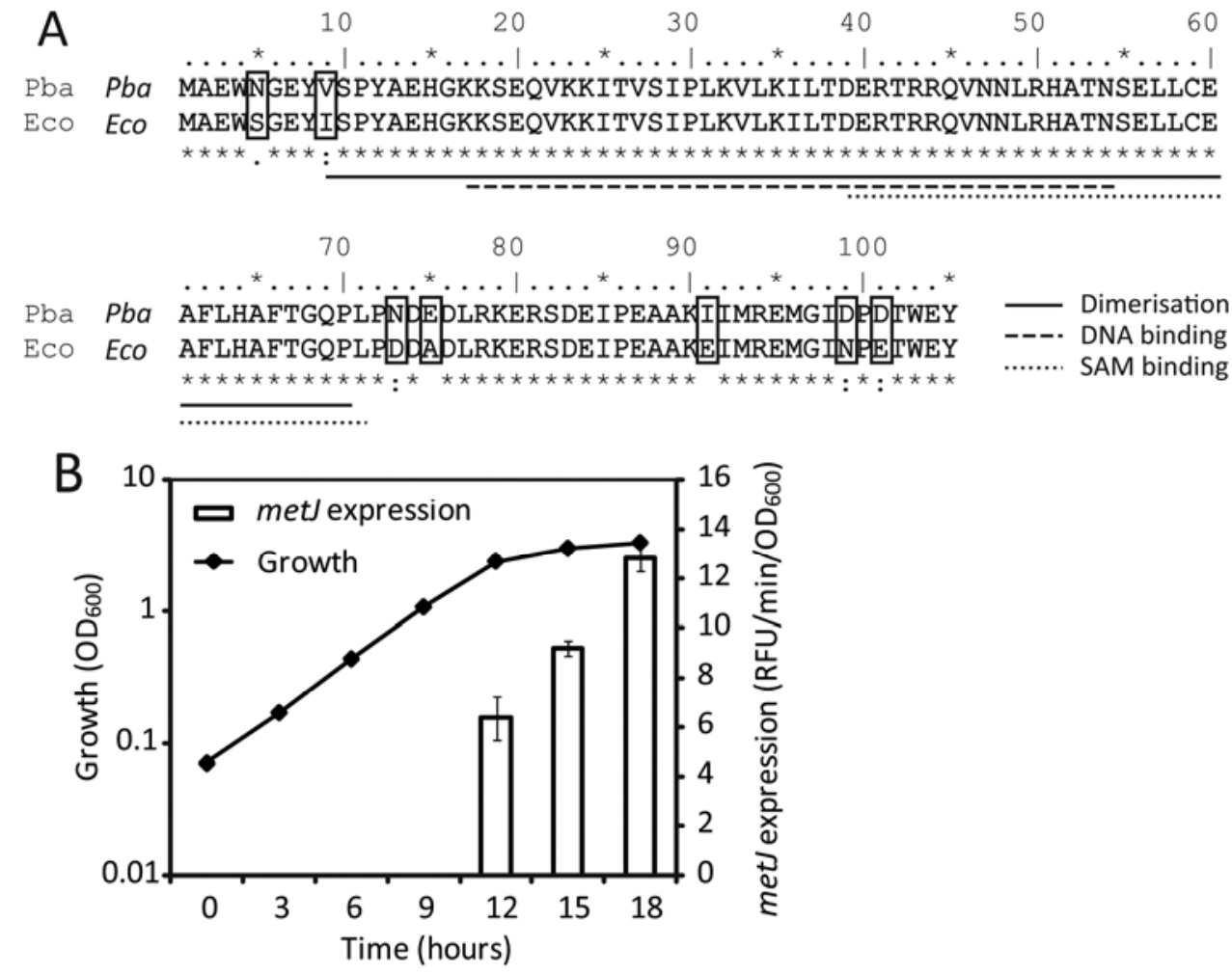

Fig. 4. A, Amino acid sequence alignment of MetJ proteins from Pectobacterium atrosepticum (Pba) and Escherichia coli (Eco). Boxes indicate an amino acid difference and lines indicate dimerization, DNA binding, and $S$-adenosylmethionine (SAM) binding domains. B, Expression of metJ throughout growth in the $\mathrm{MC} 1$ strain of $P$. atrosepticum grown in pectate minimal media at $25^{\circ} \mathrm{C}$. $\beta$-Glucuronidase expression from the reporter insertion in the $m e t J$ gene was measured by fluorescence. $\mathrm{OD}_{600}=$ optical density at $600 \mathrm{~nm}$. 
similar to other met genes, these data suggest that the transcription of this gene is under direct repression by MetJ.

The expression of genes listed in Table 1 as having a predicted met box was of particular interest as a measure of the reliability of the searching method. In addition to the expected upregulation of met genes, five other genes from Table 1 were shown to be differentially regulated in the metJ mutants (Table 2). Of particular interest are the genes ECA1405 and ECA3955, which show a very large degree of up- and downregulation, respectively, in the met $J$ mutants. Both genes encode putative $\mathrm{ABC}$ transporters but the precise substrates of these are unknown. Additional trends seen in these data include the upregulation of exoenzyme and secretion-associated genes and differential expression of the regulators $r s m A$ and $\exp R$ (Table 2). The differential expression of $\exp R$ was somewhat expected, because it follows the same pattern of expression as expI (Fig. 3D). These genes are divergently transcribed; therefore, it is likely that their expression would be co-regulated. Expression of the virR, hexY, and $k d g R$ regulatory genes was not significantly different from the wild type in any of the three mutant strains.

qRT-PCR analysis of an independent set of RNA samples confirmed many results seen in the microarray study (Table 2). Virulence-associated genes, such as those involved in secretion and those coding for exoenzymes, were downregulated in the $r s m B$ mutant but upregulated in both strains carrying the metJ mutation. However, motility-associated genes were not significantly affected in the $r \sin B$ mutant compared with the metJ mutant strains. The expression of the small regulatory RNA $r s m B$ was unchanged in the metJ mutant (data not shown). These results suggest that somehow met $J$ modulates virulence, at least in part, through increased exoenzyme secretion but inde- pendently of motility. A likely mechanism for this phenomenon could be the release of exoenzyme repression through downregulation of $\operatorname{rsm} A$ expression, which is seen in the metJ mutants.

\section{DISCUSSION}

The initial aim of this study was to isolate a transposon insertion mutant defective in the $r s m A$ gene by genetic suppression of an $r \mathrm{smB}$ mutant which had a clear $\operatorname{Prt}^{-}$phenotype. However, using the Prt restoration assay, we defined a new role for a known metabolic regulator, MetJ, in suppression of the $r s m B$ phenotype. Thus far, the metJ gene has not been linked with virulence or exoenzyme regulation in Pectobacterium spp., and most studies on MetJ have been carried out in nonpathogenic E. coli strains on the structure and function of MetJ as a DNAbinding protein and repressor. In E. coli, MetJ is known to bind to met boxes upstream of target genes involved in methionine biosynthesis. These met boxes are scattered around the chromosome and have a consensus sequence AGACGTCT. It is now well recognized that MetJ, when bound to its cofactor $S$-adenosylmethionine, binds to these sequences and inhibits target gene transcription. In a metJ mutant, this leads to constitutive expression of methionine biosynthesis genes (Weissbach and Brot 1991).

The MetJ regulon has been well studied in E. coli (Marincs et al. 2006; Old et al. 1993; Shoeman et al. 1985), and more recently in a variety of other $\gamma$-proteobacteria (Augustus and Spicer 2011). These studies show that the direct targets of MetJ regulation are almost exclusively involved in some stage of methionine biosynthesis or recycling, or that of related molecules such as $S$-adenosylmethionine or homocysteine.

Table 1. Genes preceded by a predicted "met box" sequence ${ }^{\mathrm{a}}$

\begin{tabular}{|c|c|c|c|}
\hline Gene name $^{\text {b }}$ & Gene function & $P$ value & Matched sequence \\
\hline ECA3523* & Similar to Yersinia pestis hypothetical protein & $7.3 \times 10^{7}$ & CTAGACGGCTAA \\
\hline $\operatorname{met} N$ & D-methionine transport ATP-binding protein & $7.3 \times 10^{7}$ & TTAGCCGTCTAG \\
\hline ECA1113 & Putative methionine synthase & $1.4 \times 10^{6}$ & TTAGACGTCCAG \\
\hline ECA3955 & $\mathrm{ABC}$ transporter membrane protein & $1.4 \times 10^{6}$ & TTGGACGTCTAA \\
\hline metB & Cystathionine $\gamma$-synthase & $2.3 \times 10^{6}$ & TTAGATGTCTAG \\
\hline metF & 5,10-methylenetetrahydrofolate reductase & $2.3 \times 10^{6}$ & ATAGACGTCTAA \\
\hline metJ & Repressor of the methionine regulon & $2.3 \times 10^{6}$ & CTAGACATCTAA \\
\hline metE & 5-Methyltetrahydropteroyltriglutamate-homocysteine methyltransferase & $3.1 \times 10^{6}$ & CTGGACGGCTAA \\
\hline metR & Transcriptional activator protein & $3.1 \times 10^{6}$ & TTAGCCGTCCAG \\
\hline uhpC & Putative regulatory protein & $4.7 \times 10^{6}$ & TTAGCCATCTAA \\
\hline ECA1014* & Putative membrane protein & $5.9 \times 10^{6}$ & TTAGCTGGCTAA \\
\hline$g c v A$ & Glycine cleavage system transcriptional activator & $5.9 \times 10^{6}$ & TTAGCCAGCTAA \\
\hline$y f e D$ & Chelated iron transport system membrane protein & $5.9 \times 10^{6}$ & TTAGCTGGCTAA \\
\hline ECA2069 & TetR-family transcriptional regulator & $7.5 \times 10^{6}$ & TTGGACGTCTAT \\
\hline metA & Homoserine $O$-succinyltransferase & $7.5 \times 10^{6}$ & CTGGATGTCTAA \\
\hline ECA1430 & Putative dTDP-glucose 4-6-dehydratase & $8.6 \times 10^{6}$ & TTAGACATCTAT \\
\hline ECAt014 & Protein-export membrane protein & $8.6 \times 10^{6}$ & ATAGACGTCTAT \\
\hline panE & 2-Dehydropantoate 2-reductase & $8.9 \times 10^{6}$ & CTGGACGGCCAG \\
\hline rpmJ & $50 \mathrm{~S}$ ribosomal protein & $1.5 \times 10^{5}$ & TTAGCCAGCCAA \\
\hline rps $M$ & $30 \mathrm{~S}$ ribosomal subunit protein $\mathrm{S} 13$ & $1.5 \times 10^{5}$ & TTAGCCAGCCAA \\
\hline ECA3980 & Unknown function & $1.6 \times 10^{5}$ & CTGGACGTCCAT \\
\hline ECA1912 & Putative periplasmic substrate-binding protein & $1.8 \times 10^{5}$ & ATAGCTGGCTAG \\
\hline ECA0767 & Similar to Xanthomonas hypothetical protein & $2.1 \times 10^{5}$ & ATAGACGTCCAT \\
\hline ECA1405 & Putative $\mathrm{ABC}$ sugar transporter protein & $2.1 \times 10^{5}$ & ATAGACATCCAG \\
\hline ECA2199 & Similar to Xanthomonas hypothetical protein & $2.1 \times 10^{5}$ & ATAGACGTCCAT \\
\hline ECAt065 & t-RNA glycine & $2.1 \times 10^{5}$ & ATAGACGTCCAT \\
\hline galE & Putative UDP-glucose 4-epimerase & $2.6 \times 10^{5}$ & TTACACGTCTAA \\
\hline ECA3519 & Putative acetyltransferase & $2.8 \times 10^{5}$ & TTGGACGGCCAT \\
\hline ECA3683 & Similar to $Y$. pestis hypothetical protein & $2.8 \times 10^{5}$ & CTGGACGGCCAT \\
\hline $\operatorname{pehN}$ & Putative polygalacturonase precursor & $2.8 \times 10^{5}$ & CTGGCCATCCAG \\
\hline ECA2661 & Putative membrane protein & $3.3 \times 10^{5}$ & TTGGCTATCTAG \\
\hline metK & $S$-adenosylmethionine synthetase & $3.3 \times 10^{5}$ & ATAGCCATCCAG \\
\hline
\end{tabular}

${ }^{a}$ Genes identified by a search of the Pectobacterium atrosepticum SCRI1043 genome using the MEME tool for sequences resembling the consensus $P$. atrosepticum met box TAGACGTCTA.

b Asterisk (*) indicates upstream of subsequent gene in table. 
One exception is $m e t R$, which encodes a transcriptional regulator that controls expression of a subset of the met genes, including itself (Maxon et al. 1989). Additionally, there have been recent discoveries of MetJ-regulated genes with alternative functions, such as the gene for the cobalamin transporter, $b t u B$, in E. coli (Augustus and Spicer 2011). In addition to these findings, this study reports the first link between the MetJ repressor and bacterial virulence.

The high degree of similarity between the E. coli and $P$. atrosepticum MetJ proteins, including their identical DNA binding domain, allows parallels to be drawn in the regulation of genes by MetJ in these two organisms. This is reinforced by the identification of a met box sequence nearly identical to that of the E. coli consensus. Predicted met boxes were identified in the promoter regions of a number of met genes involved in methionine biosynthesis in $P$. atrosepticum. Furthermore, the promoters of E. coli homologues of all met genes listed in Table 1 were shown to bind MetJ protein in gel shift assays (Augustus and Spicer 2011). As well as the predictions of met boxes in annotated met genes, several other genes were identified as potential regulatory targets for MetJ. Six of these genes (ECA0767, ECA1113, ECA1405, ECA2661, ECA3683, and $E C A 3955)$ were differentially expressed in the metJ mutants (Table 2). Overall, the computational method used for searching for met boxes is effective at identifying MetJ targets. However, there are many genes identified by this method which do not appear to be differentially regulated in a metJ mutant, implying a high false discovery rate. In spite of this, the transcriptomics data presented in this study better allows true targets of MetJ binding to be identified.

A particularly interesting finding from these data is that the gene ECA3955 is predicted to have a close-to-consensus met box in its promoter region (Table 1). However, microarray and qRT-PCR data suggest that the expression of this gene is downregulated by approximately 70 - and 400 -fold, respectively, in the metJ mutants (Table 2). The extent of this difference in expression strongly suggests that this effect is being mediated directly by MetJ, which implies a role in activation rather than repression of ECA3955. Because MetJ is not known to function as an activator, this is certainly an observation that warrants further study.

The large number of statistically significant changes in gene expression seen in the microarray study for strains carrying the metJ mutation indicates the pleiotropic effects of MetJ in this organism. Many of these changes, such as the upregulation of methionine biosynthesis enzymes, were expected given what is known in related bacteria. Furthermore, other genes such as those coding for major virulence regulators such as expI and $r s m A$ were differentially regulated as a cause of this mutation. There were no met box sequences identified in the upstream regions of these genes, which suggests that these changes in gene expression are likely to be mediated indirectly. Regardless of how the differential expression of these genes arises, this could be one reason for the changes observed in PCWDE and OHHL expression.

The effect of the metJ mutation on transcription of genes involved in a wide variety of cellular processes is not unexpected, because methionine metabolism is involved in the production of several metabolically important compounds, such as methylthioadenosine and $S$-adenosylmethionine (SAM). These molecules are involved in various stages in the methionine recycling pathway and feed directly into the pathways for producing adenine, polyamines, and OHHL, the QS signaling molecule (Sekowska et al. 2004). OHHL is produced by the ExpI enzyme from the precursors SAM and hexanoyl-acyl carrier protein, and several studies have demonstrated that it is SAM which is the limiting factor in this reaction. As a result, increasing the levels of SAM in the cell through upregulation of $m e t K$ could cause an increase in homoserine lactone production (Hanzelka and Greenberg 1996; Parsek et al. 1999; Val and Cronan 1998). Therefore, this could contribute to the increase in OHHL production seen in the metJ mutants.

Another important function of SAM in this context is its role as the co-repressor for MetJ. SAM is produced when the

Table 2. Selected genes differentially regulated in $r s m B$, metJ, and $r s m B$ metJ mutants ${ }^{\mathrm{a}}$

\begin{tabular}{|c|c|c|c|c|c|c|}
\hline \multirow[b]{2}{*}{ Gene name } & \multicolumn{3}{|c|}{ Microarray } & \multicolumn{3}{|c|}{ qRT-PCR } \\
\hline & $r s m B$ & metJ & rsmB, metJ & $r s m B$ & metJ & rsmB, metJ \\
\hline \multicolumn{7}{|c|}{ Met biosynthesis } \\
\hline$m e t E^{\dagger}$ & 0.47 & 94.1 & 130.6 & 4.61 & 597 & 596 \\
\hline $\operatorname{met}^{\dagger}$ & 0.84 & 93.5 & 129.0 & $\ldots$ & $\ldots$ & $\ldots$ \\
\hline$m e t R^{\dagger}$ & $0.81 *$ & 96.6 & 112.3 & & & $\ldots$ \\
\hline$m e t K^{\dagger}$ & 0.29 & 2.64 & 3.38 & 0.22 & 5.63 & 3.38 \\
\hline$E C A 1113^{\dagger}$ & 0.77 & 84.4 & 100.0 & $\ldots$ & $\ldots$ & $\ldots$ \\
\hline \multicolumn{7}{|l|}{ PCWDE } \\
\hline pelB & 0.091 & 3.42 & 2.46 & 0.14 & 11.4 & 5.09 \\
\hline pelc & 0.57 & 3.00 & 2.54 & 0.90 & 15.0 & 10.1 \\
\hline pelW & 1.09 & 4.55 & 4.98 & $\ldots$ & $\ldots$ & $\ldots$ \\
\hline celA & 1.99 & 5.24 & 5.11 & $\ldots$ & $\ldots$ & $\ldots$ \\
\hline \multicolumn{7}{|l|}{ Secretion } \\
\hline$p r t D$ & 0.25 & 17.8 & 12.9 & 0.45 & 12.8 & 4.70 \\
\hline outD & 0.42 & 4.47 & 4.50 & 0.24 & 2.63 & 1.93 \\
\hline ECA2105 & $0.77^{*}$ & 18.1 & 10.8 & 0.35 & 5.95 & 2.78 \\
\hline out $L$ & $1.13^{*}$ & 9.39 & 11.2 & $\ldots$ & $\ldots$ & $\ldots$ \\
\hline tatC & $1.17 *$ & 3.05 & 3.35 & 2.86 & 2.61 & 2.05 \\
\hline \multicolumn{7}{|l|}{ Regulators } \\
\hline rsmA & $0.92 *$ & 0.21 & 0.26 & 0.40 & 0.52 & 0.45 \\
\hline $\exp R$ & $0.39^{*}$ & 6.16 & 5.91 & 0.63 & 4.04 & 2.85 \\
\hline \multicolumn{7}{|l|}{ Other } \\
\hline ECA1405 & $1.25 *$ & 40.79 & 73.82 & $\ldots$ & $\ldots$ & $\ldots$ \\
\hline ECA2661 & 2.15 & 9.83 & 6.75 & $\ldots$ & $\ldots$ & $\ldots$ \\
\hline ECA3683 & 1.47 & 4.27 & 6.20 & $\ldots$ & $\ldots$ & $\ldots$ \\
\hline ECA0767 & $0.98 *$ & 2.51 & 2.31 & $\ldots$ & $\ldots$ & $\ldots$ \\
\hline ECA3955 & $0.91 *$ & 0.015 & 0.013 & 0.0048 & 0.0022 & 0.0026 \\
\hline
\end{tabular}

${ }^{\text {a }}$ Fold changes compared with wild type of selected genes as determined by microarray and quantitative reverse-transcriptase polymerase chain reaction (qRT-PCR). PCWDE $=$ plant cell wall-degrading enzymes, * indicates $P>0.05$, and $\dagger$ indicates gene is preceded by a "met box" sequence. 
enzymes of the MetJ regulon, such as metK, are expressed (i.e., when MetJ is unable to bind to met boxes due to either its absence or the fact that it has not formed its functional dimeric complex bound to SAM). In this way, SAM forms a link between MetJ and the production of molecules made by the enzymes that it regulates. This ties in with the pattern seen in metJ expression (Fig 4B) where, as amino acids in the growth medium become limiting in the entry to stationary phase, less SAM would be present, preventing MetJ from repressing the genes involved with methionine biosynthesis. The other transcriptional regulator within the MetJ regulon, MetR, also has a product of the methionine salvage pathway, homocysteine, as a co-repressor (Urbanowski and Stauffer 1987). Together, these co-repressors link environmental conditions to the expression of the genes in the methionine regulon.

In $P$. atrosepticum, the sensing of external conditions is vital for regulation of virulence. The QS signal OHHL provides a measure of population density, while systems such as the $\mathrm{KdgR}$ regulatory pathway indicate the presence of plant tissue breakdown products (Nasser et al. 1991). Therefore, it seems logical that a regulatory system which feeds in information concerning the state of nutrient availability could be of use in regulating a transition to virulence factor production.

Ultimately, the impact of generating a metJ mutation in an $r s m B$ mutant is the restoration of virulence. Given the modulation of $r \operatorname{sm} A$ and $\operatorname{expI}$ expression seen in metJ mutants, it is possible that a decrease in RsmA-mediated repression and an increase in QS signal production could lead to increased production of PCWDE and other virulence factors. However, because this study has shown that a restoration of the QS signal is not the sole reason for restoration of PCWDE production, there must be additional factors contributing to this effect. These factors are likely to include interplay with the Rsm system and could possibly include transcriptional regulator proteins or altered levels of metabolic products such as SAM. However, while further investigation into the precise mechanism is clearly needed, it is evident that methionine metabolism plays a hitherto unrecognized role in virulence regulation in the genus Pectobacterium and, potentially, other related species also.

\section{MATERIALS AND METHODS}

\section{Bacterial strains and growth conditions.}

The bacterial strains used in this study are given in Table 3 . Strains were grown with good aeration in Luria-Bertani (LB) or pectate minimal medium (PMM) consisting of $7 \mathrm{~g}$ of $\mathrm{K}_{2} \mathrm{HPO}_{4}, 2 \mathrm{~g}$ of $\mathrm{KH}_{2} \mathrm{PO}_{4}, 1 \mathrm{~g}$ of $\left(\mathrm{NH}_{4}\right)_{2} \mathrm{SO}_{4}, 1 \mathrm{mM} \mathrm{MgSO}{ }_{4}, 5 \mathrm{ml}$ of glycerol, and $5 \mathrm{~g}$ of polygalacturonic acid per liter. $E$. coli strains were grown at $37^{\circ} \mathrm{C}$ and $P$. atrosepticum strains were grown at $25^{\circ} \mathrm{C}$. Where appropriate, the following antibiotics were added to the media: ampicillin (Ap) to $50 \mu \mathrm{g} / \mathrm{ml}$, chloramphenicol $(\mathrm{Cm})$ to $50 \mu \mathrm{g} / \mathrm{ml}$, kanamycin $(\mathrm{Km})$ to $50 \mu \mathrm{g} / \mathrm{ml}$, spectinomycin to $50 \mu \mathrm{g} / \mathrm{ml}$, and tetracycline to $10 \mu \mathrm{g} / \mathrm{ml}$.

\section{Strain and plasmid construction.}

To make the $r s m B$ mutant strain NW155, the $5^{\prime}$ flanking region of $r \operatorname{sm} B$ was amplified with primers NW281 and NW283. The $3^{\prime}$ region was amplified with primers NW284 and NW282. These regions were joined using overlap-extension PCR with the primers NW281 and NW282. Cloning into pBluescriptKSII was via the BamHI and SalI sites to create the construct pNRW180. The $\mathrm{Km}^{\mathrm{r}}$ gene was PCR amplified from pACYC177 with primers NW279 and NW280 and subcloned into the SphI-digested and dephosphorylated construct pNRW180, creating the construct pNRW181. All primer sequences are listed in Supplementary Table S4. The $r \operatorname{smB}:: \mathrm{Km}^{\mathrm{r}}$ site was PCR amplified with primers NW281 and NW282, and the linear DNA was transformed by electroporation into Pba1043 (pKD46) using the method published by Datsenko and Wanner (2000). Stable integrants were selected on LB agar supplemented with $\mathrm{Km}$ at $50 \mu \mathrm{g} / \mathrm{ml}$. One $r s m B:: \mathrm{Km}^{\mathrm{r}}$ Pba 1043 colony was selected for further study and the $r s m B:: \mathrm{Km}$ marker was transduced into a clean genetic background using the generalized transducing phage $\Phi \mathrm{\Phi} 1$. One $\mathrm{Km}^{\mathrm{r}} \mathrm{Ap}^{\mathrm{r}}$ colony was selected and renamed NW155.

Additional strains were either made by random transposon mutagenesis or constructed by generalized transduction. Transposon mutagenesis was achieved via a conjugative plasmid loaded with the transposon TnDS1028, $\mathrm{Cm}^{\mathrm{r}}$ uidA (Smith 2005). Overnight cultures were grown of the donor ( $\beta 2163$ [pDS1028]) and recipient (NW155) strains. Cells were washed and resuspended in LB. Equal volumes of each culture were mixed and $30 \mu \mathrm{l}$ of the mixture was immediately spotted onto LB agar + $30 \mathrm{mM}$ 2,3-diaminopimelic acid. After incubation overnight at $25^{\circ} \mathrm{C}$, mating patches were resuspended in LB and serial dilutions were plated onto skimmed milk agar (nutrient broth agar, $10 \mathrm{~g}$ of Marvel skimmed milk powder per liter). Haloes indicating Prt production were visible after incubation at $25^{\circ} \mathrm{C}$ for 3 days. The transposon insertion sites were mapped using random prime PCR (Fineran et al. 2005). The generalized transducing phage $\Phi \mathrm{M} 1$ was used to move mutations between different strains of $P$. atrosepticum (Toth et al. 1997). Plasmids used to complement the metJ mutation were constructed using the pQE80L vector (Qiagen, Crawley, U.K.). Briefly, the metJ coding sequence was cloned using primers with restriction sites and inserted into the cut vector using the restriction enzymes EcoRI and PstI (New England Biosciences, Ipswich,

Table 3. Bacterial strains used in this investigation

\begin{tabular}{|c|c|c|}
\hline Strain & Genotype $^{\mathrm{a}}$ & Reference \\
\hline \multicolumn{3}{|l|}{ Escherichia coli } \\
\hline DH $5 \alpha$ & endAI, hsdR17, supE44, thi-1, recA1, gyrA96, $\Delta l a c U 169$, relA1 & \\
\hline$\beta 2163$ & $\left(\mathrm{~F}^{-}\right), \mathrm{RP} 4-2-\mathrm{Tc}:: \mathrm{Mu}$, dapA::(erm-pir $)\left[\mathrm{Km}^{\mathrm{r}} \mathrm{Em}^{\mathrm{r}}\right]$ & Demarre et al. 2005 \\
\hline JM109 (pSB401) & 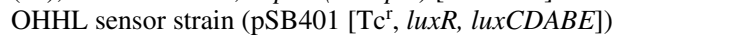 & Winson et al. 1998 \\
\hline \multicolumn{3}{|c|}{ Pectobacterium atrosepticum } \\
\hline SCRI1043 & Wild type & JHI bacterial collection \\
\hline EMS6.1 & $\mathrm{Lac}^{-}$SCRI1043 & Hinton et al. 1989 \\
\hline NW155 & $r s m B:: \mathrm{Km}^{\mathrm{r}}$ & This study \\
\hline TB6 & EMS6.1 expI::lacZ & Corbett et al. 2005 \\
\hline $\mathrm{MC1}$ & metJ $:: \operatorname{TnDS} 1028$ uidA, $\mathrm{Cm}^{\mathrm{r}}$ & This study \\
\hline MC2.1 & $\mathrm{MC} 1, r s m B:: \mathrm{Km}^{\mathrm{r}}$ & This study \\
\hline MC4 & TB6, metJ::TnDS1028uidA, $\mathrm{Cm}^{\mathrm{r}}$ & This study \\
\hline MC5 & $\mathrm{TB} 6, r s m B:: \mathrm{Km}^{\mathrm{r}}$ & This study \\
\hline MC6 & TB6, metJ::TnDS1028uidA, $\mathrm{Cm}^{\mathrm{r}}, \mathrm{rsmB}_{:}: \mathrm{Km}^{\mathrm{r}}$ & This study \\
\hline
\end{tabular}

${ }^{\mathrm{a}} \mathrm{Km}^{\mathrm{r}}, \mathrm{Em}^{\mathrm{r}}, \mathrm{Tc}^{\mathrm{r}}$, and $\mathrm{Cm}^{\mathrm{r}}=$ resistant to kanamycin, erythromycin, tetracycline, and chloramphenicol, respectively; OHHL = N-(3-oxohexanoyl)-homoserine lactone. 
MA, U.S.A.). Plasmids were introduced by electroporation as described by Evans (2009) and maintained with Ap. Artificially induced expression of cloned genes in vectors was not required, as leaky expression was sufficient for complementation.

\section{Phenotypic assays.}

Assays for PCWDE and OHHL were carried out on culture supernatant samples from cells grown in PMM. Samples of culture were taken at specified times and cells were pelleted by centrifugation. Culture supernatants were removed to a separate tube (and filter sterilized in the case of the OHHL assay) and frozen at $-80^{\circ} \mathrm{C}$ until analysis. Pel activity was measured using the method described by Coulthurst and associates (2006). Prt activity was measured using the Sigma-Aldrich Protease Fluorescent Detection Kit PF0100 according to the manufacturer's instructions, with a 4-h incubation step. OHHL was measured using the method described by Coulthurst and associates (2008). To test the effect of OHHL on exoenzyme production, $5 \mu \mathrm{l}$ of a culture of $\mathrm{OD}_{600}=1$ cells were spotted onto appropriate assay indicator plates incubated at $25^{\circ} \mathrm{C}$ for $48 \mathrm{~h}$.

\section{Virulence assays.}

Tuber virulence assays were performed on Maris Piper potato tubers according to Walker and associates (1994). Tubers were surface sterilized in $1 \%$ Virkon and stab inoculated with $10^{3}$ CFU using a sterile pipette tip. Rotting was measured by scraping out and weighing the rotted tissue. The level of rotting was expressed relative to wild-type rotting in that tuber set. Plant stem pathogenicity tests were performed in potato stems ('Estima') by inoculating 20 replicate stems with $10^{3} \mathrm{CFU}$ per inoculation site. The plants were maintained in a controlled environment room at $21^{\circ} \mathrm{C}$ for 14 days. Disease symptoms were assessed daily by measuring the length of blackleg lesion produced (Holeva et al. 2004).

\section{Transcriptional fusion assays.}

Strains containing uidA transcriptional fusions were grown in PMM for $18 \mathrm{~h}$ and culture samples taken every $3 \mathrm{~h}$ and frozen at $-80^{\circ} \mathrm{C}$. At the time of assay, samples were thawed and $10 \mu \mathrm{l}$ of each were pipetted into a round-bottomed 96-well plate. The assay was conducted according to the method of Ramsay and associates (2011) using 4-methylumbelliferyl- $\beta$ D-glucuronide at $250 \mu \mathrm{g} / \mathrm{ml}$.

\section{Computational analysis using the MEME suite.}

The 500-bp regions upstream from annotated genes were obtained from the published sequence of $P$. atrosepticum SCRI1043 (Bell et al. 2004) using the Artemis software (Rutherford et al. 2000). To identify the MetJ-binding motif using MEME (Bailey and Elkan 1994), the 500-bp upstream sequences of metA, met $C$, met $F$, meth, metJ, met $N$, metR, met $B$, $m e t E, \operatorname{met} G, \operatorname{metI}$, met $K$, and $m e t Q$ were submitted to the FIMO program (Grant et al. 2011) with the following parameters: distribution of motif occurrences $=$ any number of repetitions, number of different motifs $=3$, minimum number of sites $=2$, maximum number of sites $=7$, minimum motif width $=6$, maximum motif width $=12$, and looking for $=$ palindromes only. To identify met boxes in the chromosome, the output from the MEME analysis was submitted to FIMO comparing against the database "Erwinia_carotovora_atroseptica_SCRI1043_upstream.na" with a $P$ value display threshold of $1 \times 10^{-4}$.

\section{RNA extraction.}

Solutions for RNA work made in-house or their constituent parts were made RNase-free by treatment with $0.1 \%$ diethylpyrocarbonate (DEPC) at $37^{\circ} \mathrm{C}$ overnight, then autoclaving. For analysis throughout growth, cells were grown in PMM and 1-ml samples were taken. Cells were grown in PMM for $18 \mathrm{~h}$ and either 1-ml samples were taken throughout growth or 2-ml samples were taken at the end point. Samples were mixed with two volumes of $95 \%$ ethanol and $5 \%$ phenol and stored at $-80^{\circ} \mathrm{C}$ until extraction. RNA was isolated from samples taken throughout growth using the Qiagen RNeasy mini kit according to the manufacturer's instructions. RNA was isolated from end point samples by hot phenol extraction as described by Mattatall and Sanderson (1996). Pellets were dissolved in $100 \mu \mathrm{l}$ of DEPCtreated water. Residual DNA was removed using the Ambion TURBO DNA-free kit according to the manufacturer's instructions. Removal of DNA was confirmed by PCR on diluted RNA samples using Pba1043 16S RNA gene primers TBOL87 and TBOL88.

\section{qRT-PCR.}

RT and qRT-PCR were performed as by Burr and associates (2006). The gene $f f h$ was used as a reference gene (Takle et al. 2007) and data were normalized to wild-type expression of ffh. Relative gene expression levels were calculated using the $\Delta \Delta \mathrm{Ct}$ (cycle threshold) method (Livak and Schmittgen 2001). Independently isolated RNA templates were used in the microarray and qRT-PCR analyses.

\section{Microarray.}

RNA from stationary-phase cells was processed and hybridized to 12 custom Agilent $P$. atrosepticum microarrays (ArrayExpress accession A-MEXP-1482) using three biological replicates on separate arrays for each of the four strains. Probes were 60 mers representing each of the 4,521 P. atrosepticum SCRI1043 predicted protein coding genes, plus 23 Lucidea Universal ScoreCard controls (GE Healthcare, Piscataway, NJ, U.S.A.), and each probe was printed twice. For each array, $12 \mu \mathrm{g}$ of RNA was labeled as cDNA with Cy-3 dye (GE Healthcare) and hybridized to the array as described (Venkatesh et al. 2006). Arrays were scanned using the Agilent G2505B Scanner with $10-\mu \mathrm{m}$ resolution. Data were extracted from each scanned image using Feature Extraction (FE) software (v. 10.7; Agilent Technologies, Santa Clara, CA, U.S.A.) with default settings, prior to import into Genespring (v. 7.3; Agilent Technologies) for analysis. Complete datasets along with the array experimental design are available at ArrayExpress (accession number E-MTAB-1167). Data were normalized using default settings for Agilent one-color arrays and unreliable data removed using flags derived from FE. Significantly, differentially expressed genes between the wild type and each mutant were identified using volcano plot filtering (Students $t$ test, $P$ value $\leq 0.01$ and a minimum twofold change).

\section{ACKNOWLEDGMENTS}

We thank A. Rawlinson, S. Humphris, and R. Monson for advice and technical assistance. This study was funded by the Biotechnology and Biological Sciences Research Council and the James Hutton Institute. M. F. Cubitt, G. P. C. Salmond, N. R. Williamson, and I. K. Toth contributed to the conception and design of the study and data interpretation. All experimental work was conducted by M. F. Cubitt, unless cited otherwise, with the following exceptions. Strain NW155 was constructed by N. R. Williamson; the microarray experiment was conducted by M. F. Cubitt, I. K. Toth, P. E. Hedley, and J. Morris at the James Hutton Institute; and plant stem assays were designed by M. F. Cubitt, I. K. Toth, and E. Campbell and conducted by E. Campbell. The main body of the article was written by M. F. Cubitt, with critical revisions by all other authors. All authors have given approval for submission of the final version of the manuscript.

\section{LITERATURE CITED}

Altschul, S. F., Madden, T. L., Schäffer, A. A., Zhang, J., Zhang, Z., Miller, W., and Lipman, D. J. 1997. Gapped BLAST and PSI-BLAST: A new 
generation of protein database search programs. Nucleic Acids Res. 25:3389-3402.

Apagyi, K. 2012. Characterization of a novel virulence determinant in Erwinia carotovora subspecies atroseptica SCRI1043. Ph.D. thesis, University Library, University of Cambridge, Cambridge, U.K.

Augustus, A. M., and Spicer, L. D. 2011. The MetJ regulon in gammaproteobacteria determined by comparative genomics methods. BMC Genomics 12:558.

Bailey, T. L., and Elkan, C. 1994. Fitting a mixture model by expectation maximization to discover motifs in biopolymers. Proc. Int. Conf. Intell. Syst. Mol. Biol. 2:28-36.

Barnard, A. M., Bowden, S. D., Burr, T., Coulthurst, S. J., Monson, R. E. and Salmond, G. P. 2007. Quorum sensing, virulence and secondary metabolite production in plant soft-rotting bacteria. Philos. Trans. R. Soc. Lond. B Biol. Sci. 362:1165-1183.

Belfaiza, J., Parsot, C., Martel, A., de la Tour, C. B., Margarita, D., Cohen, G. N., and Saint-Girons, I. 1986. Evolution in biosynthetic pathways: Two enzymes catalyzing consecutive steps in methionine biosynthesis originate from a common ancestor and possess a similar regulatory region. Proc. Natl. Acad. Sci. U.S.A. 83:867-871.

Bell, K. S., Sebaihia, M., Pritchard, L., Holden, M. T., Hyman, L. J., Holeva, M. C., Thomson, N. R., Bentley, S. D., Churcher, L. J., Mungall, K., Atkin, R., Bason, N., Brooks, K., Chillingworth, T., Clark, K., Doggett, J., Fraser, A., Hance, Z., Hauser, H., Jagels, K., Moule, S., Norbertczak, H., Ormond, D., Price, C., Quail, M. A., Sanders, M. Walker, D., Whitehead, S., Salmond, G. P., Birch, P. R., Parkhill, J., and Toth, I. K. 2004. Genome sequence of the enterobacterial phytopathogen Erwinia carotovora subsp. atroseptica and characterization of virulence factors. Proc. Natl. Acad. Sci. U.S.A. 101:11105-11110.

Burr, T., Barnard, A. M., Corbett, M. J., Pemberton, C. L., Simpson, N. J., and Salmond, G. P. 2006. Identification of the central quorum sensing regulator of virulence in the enteric phytopathogen, Erwinia carotovora: The VirR repressor. Mol. Microbiol. 59:113-125.

Corbett, M., Virtue, S., Bell, K., Birch, P., Burr, T., Hyman, L., Lilley, K. Poock, S., Toth, I., and Salmond, G. 2005. Identification of a new quorum-sensing-controlled virulence factor in Erwinia carotovora subsp. atroseptica secreted via the type II targeting pathway. Mol. Plant-Microbe Interact. 18:334-342.

Coulthurst, S. J., Lilley, K. S., and Salmond, G. P. C. 2006. Genetic and proteomic analysis of the role of $\operatorname{luxS}$ in the enteric phytopathogen, Erwinia carotovora. Mol. Plant Pathol. 7:31-45.

Coulthurst, S. J., Lilley, K. S., Hedley, P. E., Liu, H., Toth, I. K., and Salmond, G. P. 2008. DsbA plays a critical and multifaceted role in the production of secreted virulence factors by the phytopathogen Erwinia carotovora subsp. atroseptica. J. Biol. Chem. 283:23739-23753.

Cui, Y., Chatterjee, A., Liu, Y., Dumenyo, C. K., and Chatterjee, A. K. 1995. Identification of a global repressor gene, rsmA, of Erwinia carotovora subsp. carotovora that controls extracellular enzymes, $\mathrm{N}-(3-$ oxohexanoyl)-L-homoserine lactone, and pathogenicity in soft-rotting Erwinia spp. J. Bacteriol. 177:5108-5115.

Datsenko, K. A., and Wanner, B. L. 2000. One-step inactivation of chromosomal genes in Escherichia coli K-12 using PCR products. Proc. Natl. Acad. Sci. U.S.A. 97:6640-6645.

Demarre, G., Guérout, A., Matsumoto-Mashimo, C., Rowe-Magnus, D. A., Marliere, P., and Mazel, D. 2005. A new family of mobilizable suicide plasmids based on broad host range R388 plasmid (IncW) and RP4 plasmid (IncP $\alpha)$ conjugative machineries and their cognate Escherichia coli host strains. Res. Microbiol. 156:245-255.

Evans, T. J. 2009. Investigation of bacteriophages and their use in the analysis of enterobacterial virulence. Ph.D. thesis, University Library, University of Cambridge, Cambridge, U.K.

Fineran, P. C., Everson, L., Slater, H., and Salmond, G. P. C. 2005. A GntR family transcriptional regulator (PigT) controls gluconate-mediated repression and defines a new, independent pathway for regulation of the tripyrrole antibiotic, prodigiosin, in Serratia. Microbiology 151:38333845 .

Fuqua, W. C., Winans, S. C., and Greenberg, E. P. 1994. Quorum sensing in bacteria: The LuxR-LuxI family of cell density-responsive transcriptional regulators. J. Bacteriol. 176:269-275.

Grant, C. E., Bailey, T. L., and Noble, W. S. 2011. FIMO: Scanning for occurences of a given motif. Bioinformatics. 27: 1017-1018.

Hanzelka, B. L., and Greenberg, E. P. 1996. Quorum sensing in Vibrio fischeri: Evidence that S-adenosylmethionine is the amino acid substrate for autoinducer synthesis. J. Bacteriol. 178:5291-5294.

Hinton, J. C., Sidebotham, J. M., Hyman, L. J., Perombelon, M. C., and Salmond, G. P. 1989. Isolation and characterisation of transposoninduced mutants of Erwinia carotovora subsp. atroseptica exhibiting reduced virulence. Mol. Gen. Genet. 217:141-148.

Holeva, M. C., Bell, K. S., Hyman, L. J., Avrovra, A. O., Whisson, S. C., Birch, P. R., and Toth, I. K. 2004. Use of a pooled transposon mutation grid to demonstrate roles in disease development for Erwinia carotovora subsp. atroseptica putative type III secreted effector (DspE/A) and helper $(\mathrm{HrpN})$ proteins. Mol. Plant-Microbe Interact. 17:943-950.

Langridge, G. C., Phan, M. D., Turner, D. J., Perkins, T. T., Parts, L., Haase, J., Charles, I., Maskell, D. J., Peters, S. E., Dougan, G., Wain, J., Parkhill, J., and Turner, A. K. 2009. Simultaneous assay of every Salmonella Typhi gene using one million transposon mutants. Genome Res. 19:2308-2316.

Lapouge, K., Schubert, M., Allain, F. H., and Haas, D. 2008. Gac/Rsm signal transduction pathway of gamma-proteobacteria: From RNA recognition to regulation of social behaviour. Mol. Microbiol. 67:241-253.

Liu, H., Coulthurst, S. J., Pritchard, L., Hedley, P. E., Ravensdale, M., Humphris, S., Burr, T., Takle, G., Brurberg, M. B., Birch, P. R. Salmond, G. P., and Toth, I. K. 2008. Quorum sensing coordinates brute force and stealth modes of infection in the plant pathogen Pectobacterium atrosepticum. PLoS Pathog. 4:e1000093.

Liu, Y., Cui, Y., Mukherjee, A., and Chatterjee, A. K. 1998. Characterization of a novel RNA regulator of Erwinia carotovora ssp. carotovora that controls production of extracellular enzymes and secondary metabolites. Mol. Microbiol. 29:219-234.

Livak, K. J., and Schmittgen, T. D. 2001. Analysis of relative gene expression data using real-time quantitative PCR and the 2(-Delta Delta C(T)) method. Methods 25:402-408.

Marincs, F., Manfield, I. W., Stead, J. A., McDowall, K. J., and Stockley, P. G. 2006. Transcript analysis reveals an extended regulon and the importance of protein-protein co-operativity for the Escherichia coli methionine repressor. Biochem. J. 396:227-234.

Mattatall, N. R., and Sanderson, K. E. 1996. Salmonella typhimurium LT2 possesses three distinct $23 \mathrm{~S}$ rRNA intervening sequences. J. Bacteriol. 178:2272-2278

Maxon, M. E., Redfield, B., Cai, X. Y., Shoeman, R., Fujita, K., Fisher, W., Stauffer, G., Weissbach, H., and Brot, N. 1989. Regulation of methionine synthesis in Escherichia coli: Effect of the MetR protein on the expression of the metE and metR genes. Proc. Natl. Acad. Sci. U.S.A. 86:85-89.

Miller, M. B., and Bassler, B. L. 2001. Quorum sensing in bacteria. Annu. Rev. Microbiol. 55:165-199.

Monson, R. E., Burr, T., Carlton, T., Liu, H., Hedley, P., Toth, I., and Salmond, G. 2012. Identification of genes in the VirR regulon of Pectobacterium atrosepticum and characterization of their roles in quorum sensing dependent virulence. Environ. Microbiol. Published online. doi:10.1111/j.1462-2920.2012.02822.x

Nasser, W., Condemine, G., Plantier, R., Anker, D., and Robert-Baudony, J. 1991. Inducing properties of analogs of 2-keto-3-deoxygluconate on the expression of pectinase genes of Erwinia chrysanthemi. FEMS (Fed. Eur. Microbiol. Soc.) Microbiol. Lett. 65:73-38.

Old, I. G., Saint Girons, I., and Richaud, C. 1993. Physical mapping of the scattered methionine genes on the Escherichia coli chromosome. J. Bacteriol. 175:3689-3691.

Parsek, M. R., Val, D. L., Hanzelka, B. L., Cronan, J. E., Jr., and Greenberg, E. P. 1999. Acyl homoserine-lactone quorum-sensing signal generation. Proc. Natl. Acad. Sci. U.S.A. 96:4360-4365.

Ramsay, J. P., Williamson, N. R., Spring, D. R., and Salmond, G. P. 2011. A quorum-sensing molecule acts as a morphogen controlling gas vesicle organelle biogenesis and adaptive flotation in an enterobacterium. Proc. Natl. Acad. Sci. U.S.A. 108:14932-14937.

Romeo, T. 1998. Global regulation by the small RNA-binding protein CsrA and the non-coding RNA molecule CsrB. Mol. Microbiol. 29:1321-1330.

Romeo, T., Gong, M., Liu, M. Y., and Brun-Zinkernagel, A. M. 1993. Identification and molecular characterization of $\operatorname{csr}$, a pleiotropic gene from Escherichia coli that affects glycogen biosynthesis, gluconeogenesis, cell size, and surface properties. J. Bacteriol. 175:4744-4755.

Rutherford, K., Parkhill, J., Crook, J., Horsnell, T., Rice, P., Rajandream, M. A., and Barrell, B. 2000. Artemis: Sequence visualization and annotation. Bioinformatics 16:944-945.

Sekowska, A., Dénervaud, V., Ashida, H., Michoud, K., Haas, D., Yokota, A., and Danchin, A. 2004. Bacterial variations on the methionine salvage pathway. BMC Microbiol. 4:9.

Shih, Y. L., Harris, S. J., Borner, G., Rivet, M. M., and Salmond, G. P. 1999. The hexY genes of Erwinia carotovora ssp. carotovora and ssp. atroseptica encode novel proteins that regulate virulence and motility co-ordinately. Environ. Microbiol. 1:535-547.

Shoeman, R., Coleman, T., Redfield, B., Greene, R. C., Smith, A. A., Saint-Girons, I., Brot, N., and Weissbach, H. 1985. Regulation of methionine synthesis in Escherichia coli: Effect of metJ gene product and $\mathrm{S}$-adenosylmethionine on the in vitro expression of the metB, met $L$ and metJ genes. Biochem. Biophys. Res. Commun. 133:731-739.

Smith, D. S. 2005. Development of a positive selection strategy to investigate the regulation of quorum sensing in Erwinia. Ph.D. thesis, Univer- 
sity Library, University of Cambridge, Cambridge, U.K.

Takle, G. W., Toth, I. K., and Brurberg, M. B. 2007. Evaluation of reference genes for real-time RT-PCR expression studies in the plant pathogen Pectobacterium atrosepticum. BMC Plant Biol. 7:50.

Timmermans, J., and Van Melderen, L. 2009. Conditional essentiality of the $\operatorname{csr}$ A gene in Escherichia coli. J. Bacteriol. 191:1722-1724.

Toth, I. K., and Birch, P. R. 2005. Rotting softly and stealthily. Curr. Opin. Plant Biol. 8:424-429.

Toth, I. K., Mulholland, V., Cooper, V., Bentley, S., Shih, Y. L., Perombelon, M. C. M., and Salmond, G. P. C. 1997. Generalized transduction in the potato blackleg pathogen Erwinia carotovora subsp. atroseptica by bacteriophage M1. Microbiology 143:2433-2438.

Urbanowski, M. L., and Stauffer, G. V. 1987. Regulation of the metR Gene of Salmonella typhimurium. J. Bacteriol. 169:5841-5844.

Val, D. L., and Cronan, J. E., Jr. 1998. In vivo evidence that S-adenosylmethionine and fatty acid synthesis intermediates are the substrates for the LuxI family of autoinducer synthases. J. Bacteriol. 180:2644-2651.

Venkatesh, B., Babujee, L., Liu, H., Hedley, P., Fujikawa, T., Birch, P., Toth, I., and Tsuyumu, S. 2006. The Erwinia chrysanthemi 3937 PhoQ sensor kinase regulates several virulence determinants. J. Bacteriol. 188:3088-3098.

Walker, D., Reeves, P. J., and Salmond, G. 1994. The major secreted cellulase, CelV, of Erwinia carotovora subsp. carotovora is an important soft rot virulence factor. Mol. Plant-Microbe Interact. 7:7

Wei, B., Brun-Zinkernagel, A., Simecka, J. W., Pruss, B. M., Babitzke, P., and Romeo, T. 2001. Positive regulation of motility and flhDC expression by the RNA-binding protein CsrA of Escherichia coli. Mol. Microbiol. 40:245-256.

Weissbach, H., and Brot, N. 1991. Regulation of methionine synthesis in Escherichia coli. Mol. Microbiol. 5:1593-1597.

Whitehead, N. A., Byers, J. T., Commander, P., Corbett, M. J., Coulthurst, S. J., Everson, L., Harris, A. K., Pemberton, C. L., Simpson, N. J., Slater, H., Smith, D. S., Welch, M., Williamson, N., and Salmond, G. P. 2002. The regulation of virulence in phytopathogenic Erwinia species: Quorum sensing, antibiotics and ecological considerations. Antonie Leeuwenhoek. 81:223-231.

Winson, M. K., Swift, S., Fish, L., Throup, J. P., Jorgensen, F., Chhabra, S. R., Bycroft, B. W., Williams, P., and Stewart, G. S. 1998. Construction and analysis of $l u x C D A B E$-based plasmid sensors for investigating $\mathrm{N}$-acyl homoserine lactone-mediated quorum sensing. FEMS (Fed. Eur. Microbiol. Soc.) Microbiol. Lett. 163:185-192.

\section{AUTHOR-RECOMMENDED INTERNET RESOURCE}

ArrayExpress database: www.ebi.ac.uk/arrayexpress 